\title{
Flow Characteristic and Trapping Characteristics of Cycloid Rotor Pump
}

\author{
Ren Zhenxing ${ }^{*},{ }^{1}$, Liu Chunyan ${ }^{2}$ and Li Yulong ${ }^{1}$ \\ ${ }^{1}$ Industrial Manufacturing School, Chengdu University, Chengdu, Sichuan 610106, China \\ ${ }^{2}$ Safety, Environment \& Technology Supervision Research Institute, PetroChina Southwest Oil \& Gasfield Company, \\ Chengdu, Sichuan 610041, China
}

\begin{abstract}
To accurately calculate the flow rate of cycloid rotary pump as well as to correctly understand its trapped oil phenomenon, firstly the instantaneous flow rate formula of cycloid rotary pump was established based on the method of swept area, and then it was compared with the two present approximate formulas by an example. Secondly, based on the established flow rate formula and the created trapped oil model in the present literature, the trapped oil pressure of a single cavity near the minimum volume position was simulated. It was pointed that for cycloid rotary pump as an example, the flow non-uniform coefficient was $6.45 \%$, and in contrast, the flow non-uniformity coefficient of external gear pump was $21.2 \%$. Relative to the accurate results, the two present approximate errors of flow rates were $1.93 \%$ and $2.90 \%$; and the present approximate error of flow non-uniform coefficient was $7.13 \%$; when the minimum position angle was added by $0.5^{\circ}$ or $1^{\circ}$ or $2^{\circ}$, relative to discharge pressure of the pump, the corresponding maximum peak of trapped oil pressure increased by $1.6 \%$ or $6.0 \%$ or $21.7 \%$. The results indicate that the flow characteristics of cycloid rotary pump are better than the external gear pump, the two present approximate errors of flow rate are little but the present approximate error of flow non-uniform coefficient is higher. Also, there is a trapped oil phenomenon in cycloid rotary pump which is not obvious.
\end{abstract}

Keywords: Cycloid rotary pump, flow characteristics, simulation, swept area, trapped oil characteristics, trapped oil model, trapped oil pressure.

As an internal cycloid gear pump ("cycloid rotor pump" for short) having a mesh with tooth difference, its characteristics include taking the equidistant curve of complete curtate epicycloid as the inner rotor tooth profile, and the outer rotor tooth profile as circular arc profile conjugated with it. The pump is widely used in the various hydraulic systems including the vehicles [1], due to its advantages as compact size, simple structure, stable operation, small noise and good high-speed performance. In the recent decades, a number of studies have been carried out on it at home and abroad. According to the literature [2], the tooth profile envelope forming method of the cycloid pump was studied on the basis of the envelope theory in the differential geometry; the production method of cyclical toothing and spiral rotor and their geometry were studied with the gear pump and the cycloidal toothing on the roots blower [3]; the geometric correction method of the cycloidal profile was proposed [4]; moreover, a study was carried out on the curve and the formation of its envelope line with the principle of gear meshing and differential geometry theory from different aspects [5-11]. The foreign scholars mainly focus on studying the meshing theory of tooth profile and there have been relatively few studies on the actual application problem. Furthermore, according to the literature [12-15], a study was carried out on the determination

\footnotetext{
*Address correspondence to this author at the Industrial Manufacturing School, Chengdu University, Chengdu, Sichuan 610106, China; Tel: +86-028-84616023; Fax: +86-028-84616023; E-mail:2464798529@qq.com
}

of the meshing clearance and its tooth profile design and influence of pressure distribution. The domestic literature mainly reflects the study and design of tooth profile $[1,16-$ 18], the parameter selection and optimization [19-21]. A detailed study and simulation calculation were carried out on the pump theory [1]; and the volume of its working cavity was calculated and analyzed [21], however the computational process was too complicated, therefore, the practicability was not strong. Since the tooth form of the inner and outer rotors is relatively complicated, there are not many studies on the flow (displacement) characteristics of the pump currently, and in the actual application, the approximation formula is mostly used for calculating [22]. For the trapping phenomenon, it is thought that the trapping phenomenon is not presented by the internal meshing pump in the common sense; however the trapping phenomenon of the internal gear pump is studied and described in the literature and in part of network data [23]. Based on the view, this paper has carried out further study on the flow characteristics and trapping characteristics of the pump, so as to obtain the accurate flow calculation formula and to correctly understand the trapping phenomenon of the pump.

\section{FLOW CHARACTERISTICS}

Fig. (1) describes three positions of the cycloid rotor pump in a complete oil absorption process. Fig. (1a) indicates the minimum volume position of a working cavity, called minimum position; in Fig. (1c), the maximum volume 
position of a working cavity is indicated, called maximum position; and in Fig. (1b), one unspecific volume position of a working cavity between the maximum and minimum is indicated, called one unspecific position. The formed meshing points of a working cavity are set as $n_{1}$ and $n_{2}$ respectively, the volume is set as $V_{1}$, the inner rotor is called the wheel $o_{1}$, and the outer rotor is called the wheel $o_{2}$, wherein the wheel $o_{1}$ and the wheel $o_{2}$ refer to the corresponding wheel centers.

In Fig. (1b), the angles of the wheel o1 and o2 turn are set as $\mathrm{d} \varphi_{1}$ and $\mathrm{d} \varphi_{2}$ in the small time dt. At this time, the small variation $\mathrm{d} V_{1}$ of $V_{1}$ is

$$
\mathrm{d} V_{1}=0.5 b\left(r_{11}^{2}-r_{21}^{2}\right) \mathrm{d} \varphi_{1}+0.5 b\left(r_{12}^{2}-r_{22}^{2}\right) \mathrm{d} \varphi_{2}
$$

In the formula, $r_{11}$ and $r_{12}$ indicate the distance from the point $n_{1}$ to the wheel center $o_{1}$ and $o_{2} ; r_{21}$ and $r_{22}$ indicate the distance from $n_{2}$ to $o_{1}$ and $o_{2} ; b$ indicates the tooth width; and $\varphi_{1}$ and $\varphi_{2}$ indicate the included angle between $x_{1}$ axis and $x_{2}$ axis of the dynamic coordinate and $x_{1} O_{1} y_{1}$ and $x_{2} O_{2} y_{2}$ of the wheel $o_{1}$ and $o_{2}$ and the $x$ axis of the fixed coordinate system $\mathrm{xo}_{2} y$ respectively, namely, the rotation angle of the wheel $o_{1}$ and $o_{2}$. When $\varphi_{2}=0, x_{1}$ axis and $x_{2}$ axis coincide with the $\mathrm{x}$ axis.

In Fig. (1b), if the drop foot of $n_{1}$ and $n_{2}$ on the center line $o_{1} O_{2}$ is set as $\mathrm{k}_{1}$ and $\mathrm{k}_{2}$, it exists in the right triangle $\Delta \mathrm{o} 2$ $\mathrm{n}_{1} \mathrm{k}_{1}$ and $\Delta \mathrm{pn}_{1} \mathrm{k}_{1}$

$r_{11}^{2}-\left(r_{1}-k_{p 1}\right)^{2}=l_{1}^{2}=f_{1}^{2}-k_{p 1}^{2}$

In the formula, $r_{1}$ indicates the pitch radius of $o_{1} ; f_{1}$ and $\mathrm{k}_{\mathrm{p} 1}$ indicate the length from the node $\mathrm{p}$ to the point $\mathrm{n}_{1}$ and point $\mathrm{k}_{1}$; and $\mathrm{l}_{1}$ indicates the length from $\mathrm{n}_{1}$ to $\mathrm{k}_{1}$. Similarly,

$$
\left.\begin{array}{l}
r_{12}^{2}-\left(r_{2}-k_{p 1}\right)^{2}=l_{1}^{2}=f_{1}^{2}-k_{p 1}^{2} \\
r_{21}^{2}-\left(r_{1}-k_{p 2}\right)^{2}=l_{2}^{2}=f_{2}^{2}-k_{p 2}^{2} \\
r_{22}^{2}-\left(r_{2}-k_{p 2}\right)^{2}=l_{2}^{2}=f_{2}^{2}-k_{p 2}^{2}
\end{array}\right\}
$$

In the formula, $\mathrm{r}_{2}$ indicates the pitch radius of $\mathrm{o}_{2} ; \mathrm{f}_{2}$ and $\mathrm{k}_{\mathrm{p} 2}$ indicate the length from the point $\mathrm{p}$ to the point $\mathrm{n}_{2}$ and point $\mathrm{k}_{2}$; and $\mathrm{l}_{2}$ indicates the length from $\mathrm{n}_{2}$ to $\mathrm{k}_{2}$.

$z_{1}$ and $z_{2}$ are set as the tooth numbers of the gear $o_{1}$ and $\mathrm{o}_{2} ; \mathrm{i}$ is set as the transmission ratio; $\omega_{1}$ and $\omega_{2}$ are set as the angular speeds of the wheel $\mathrm{o}_{1}$ and $\mathrm{o}_{2}$, therefore, for the cycloid rotor pump, it has:

$i=z_{1} / z_{2}=r_{1} / r_{2}=\mathrm{d} \varphi_{2} / \mathrm{d} \varphi_{1}=\varphi_{2} / \varphi_{1}=\omega_{2} / \omega_{1}$

By substituting the formulae (2)-(4) into the formula (1), the change rate $\mathrm{DV}_{1}$ of $\mathrm{V}_{1}$ to time can be derived as follows

$\mathrm{D} V_{1}\left(\varphi_{2}\right)=\mathrm{d} V_{1} / \mathrm{d} t=0.5(1-i) \omega_{1} b\left[f_{1}^{2}\left(\varphi_{2}\right)-f_{2}^{2}\left(\varphi_{2}\right)\right]$

In Fig. (1b), $c_{1}$ and $c_{2}$ indicate the center of circle of two adjacent formed generating circles of V1. Since $\angle \mathrm{c}_{1} \mathrm{O}_{2} \mathrm{c}_{2}=$ $2 \pi / \mathrm{z}_{2}, \angle \mathrm{c}_{2} \mathrm{O}_{2} \mathrm{X}=\varphi_{2}-2 \pi / \mathrm{z}_{2}$. Therefore, in the triangles $\Delta \mathrm{o}_{2} \mathrm{c}_{1} \mathrm{p}$ and $\Delta \mathrm{o}_{2} \mathrm{c}_{2} \mathrm{p}$, it has

$$
\left.\begin{array}{l}
f_{1}\left(\varphi_{2}\right)=\sqrt{L^{2}+r_{2}^{2}-2 L r_{2} \cos \varphi_{2}}-R \\
f_{2}\left(\varphi_{2}\right)=f_{1}\left(\varphi_{2}-2 \pi / z_{2}\right)
\end{array}\right\}
$$

In the formula, $\mathrm{L}$ indicates the radius of the generating circle; and $\mathrm{R}$ indicates the radius of the enveloping circle.

If $\varphi_{2}=\pi / z_{2}$ in Fig. (1a) and $\varphi_{2}=\pi+\pi / z_{2}$ in Fig. (1c), the total output flow Qsh of the pump is the sum of all positive or negative $\mathrm{DV}_{1}$ in a circle according to the volume of $\mathrm{z}_{2}$ single working cavities in a circle as the wheel $\mathrm{O}_{2}$ rotates, namely

$$
Q_{s h}\left(\varphi_{2}\right)=\sum_{j=1}^{z_{2}} \mathrm{D} V_{1}\left[\varphi_{2}-(j-1) 2 \pi / z_{2}\right] \quad\left(\mathrm{D} V_{1} \geq 0\right)
$$

\section{INSTANCE ANALYSIS OF FLOW CHARACTERISTICS}

The center distance, i.e. $\mathrm{e}=2.5^{*} 10^{-3} \mathrm{~m}, \mathrm{z}_{1}=6, \mathrm{z}_{2}=7$, $\mathrm{R}=8.8 * 10^{-3} \mathrm{~m}, \mathrm{~L}=24.5^{*} 10^{-3} \mathrm{~m}, \mathrm{~b}=20^{*} 10^{-3} \mathrm{~m}$, is used; the speed of the wheel $\mathrm{o}_{1}$ is $2000 \mathrm{r} / \mathrm{min}$, and its geometric calculation is shown in the literature [19]. The corresponding $\mathrm{DV}_{1}$ and $\mathrm{Q}_{\text {sh }}$ under the above parameters are shown in Fig. $(\mathbf{2 a}, \mathbf{b})$. It can be seen from Fig. (2) that $\mathrm{DV}_{1}$ (shown in the small circle 1 in figure) near the minimum position is gentle, relative to that (shown in the small circle 2 in figure) near the maximum position. It can be seen from Fig. (2b) that the maximum flow is $3.293 \times 10^{-4} \mathrm{~m}^{3} / \mathrm{s}$, the minimum flow is $3.085 \times 10^{-4} \mathrm{~m}^{3} / \mathrm{s}$, and the average flow is $3.226 \times 10^{-4} \mathrm{~m}^{3} / \mathrm{s}$, so the non-uniform coefficient of the flow is $\delta=(3.293-3.085) /$

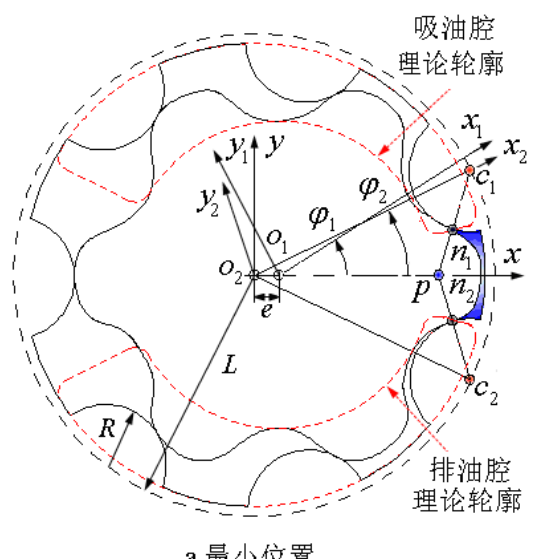

a. The minimum position

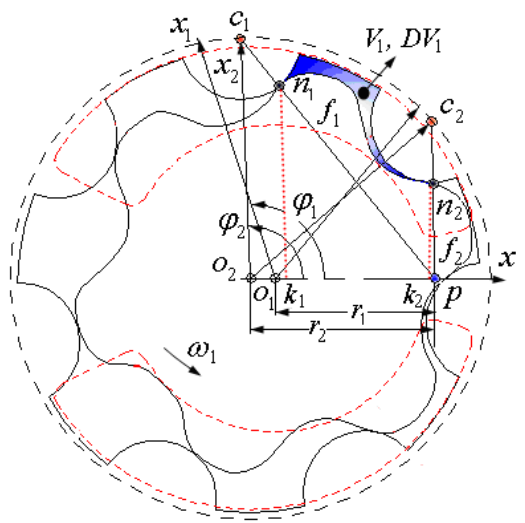

b. 某一位置

b. A certain position

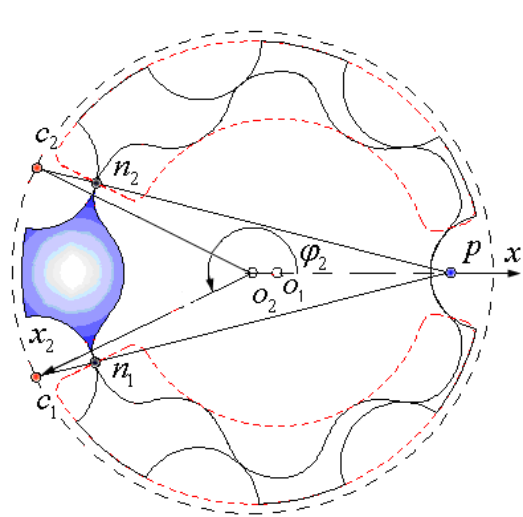

c. 最大位置

c. The maximum position

Fig. (1). Minimum volume and maximum volume and one unspecific position of a working cavity. 
$3.226=6.45 \%$, which is much more stable than the nonuniform coefficient of $21.2 \%$ flow for the external gear pump with the tooth number of 10 [22], and the pulse frequency ${ }_{Q}=n_{2} z_{2} / 60$ of the flow is consistent with that of the external gear pump which is provided with the side clearance [22], wherein $\mathrm{n}_{2}$ indicates the speed of the wheel $\mathrm{o}_{2}$.

The approximate calculation formula of the two flows given in the literature [22] and their non-uniform coefficients are as follows:

$$
\left.\begin{array}{rl}
Q_{s 1} & =0.5 \omega_{1} b\left(r_{a 1}^{2}-r_{f 1}^{2}\right) \\
Q_{s 2} & =0.5 \omega_{1} b r_{f 2}^{2}[0.5687-0.0333(L-R) / e] \\
\delta_{s} & =[16.5-2.36(L-R) / e+0.44 L / e] \%
\end{array}\right\}
$$

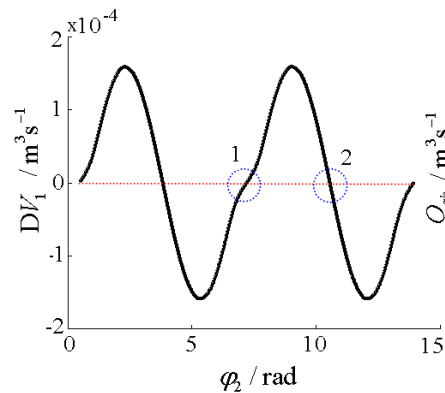

a. 单工作腔容积变化率

a. The changed rate of working volume

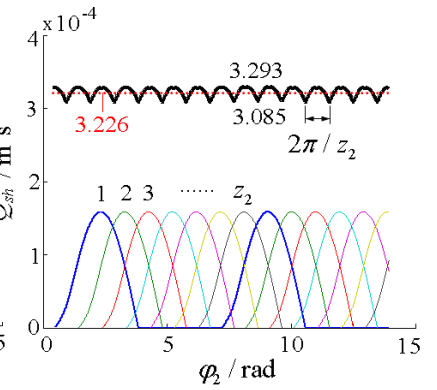

b. 瞬时流量

b. The instantaneous flow rate
Fig. (2). Changed volume rate of a working cavity and total instantaneous flow.

After the calculation, $\mathrm{Q}_{\mathrm{s1}}=3.288^{*} 10^{-4} \mathrm{~m}^{3} / \mathrm{s} ; \quad \mathrm{Qs} 2=$ $3.227 * 10^{-4} \mathrm{~m}^{3} / \mathrm{s}$; and $\delta_{\mathrm{s}}=5.99 \%$. Two approximation errors of the flow are $1.93 \%$ and $2.90 \%$ respectively; and the approximation error of the non-uniform coefficient of the flow is $7.13 \%$, wherein the approximation error of the flow is relatively small, and the approximation error of the nonuniform coefficient of the flow is on the high side.

\section{TRAPPING CHARACTERISTICS}

\subsection{Trapping Model}

The working pressure of oil in $V_{1}$ is set as $p_{1}$, and if the volume increase of V1 is positive, it is obtained as follows according to the definition of the elasticity modulus of the fluid [24-27].

$$
\mathrm{d} p_{1} / \mathrm{d} t=K_{1}\left[-\mathrm{D} V_{1}-Q_{n}\left(p_{1}\right)-Q_{o}\left(p_{1}\right)-Q_{r}\left(p_{1}\right)\right] / V_{1}
$$

In the formula, $\mathrm{K}_{1}$ indicates the bulk modulus of the oil; $\mathrm{Q}_{\mathrm{n}}$ indicates the exchange flow that the inside and outside of $\mathrm{V}_{1}$ pass through the meshing clearance at the point $\mathrm{n}_{1}$ and $\mathrm{n}_{2}$; $\mathrm{Q}_{\mathrm{o}}$ indicates the exchange flow that the inside and outside of $\mathrm{V}_{1}$ pass through the axial clearance of the end face; and $\mathrm{Q}_{\mathrm{r}}$ indicates the exchange flow between $\mathrm{V}_{1}$ and outside oil absorption cavity and oil drainage cavity. And $-\mathrm{DV}_{1}$ is marked as the trapped oil flow.

The theoretical crescent oil absorption cavity and oil drainage cavity of the pump can be opened into the form shown in Figs. $(\mathbf{1}, \mathbf{3})$, and the oil absorption cavity and oil drainage cavity are arranged symmetrically. The included angle of the oil cavity with $\mathrm{x}$ axis in the minimum position is

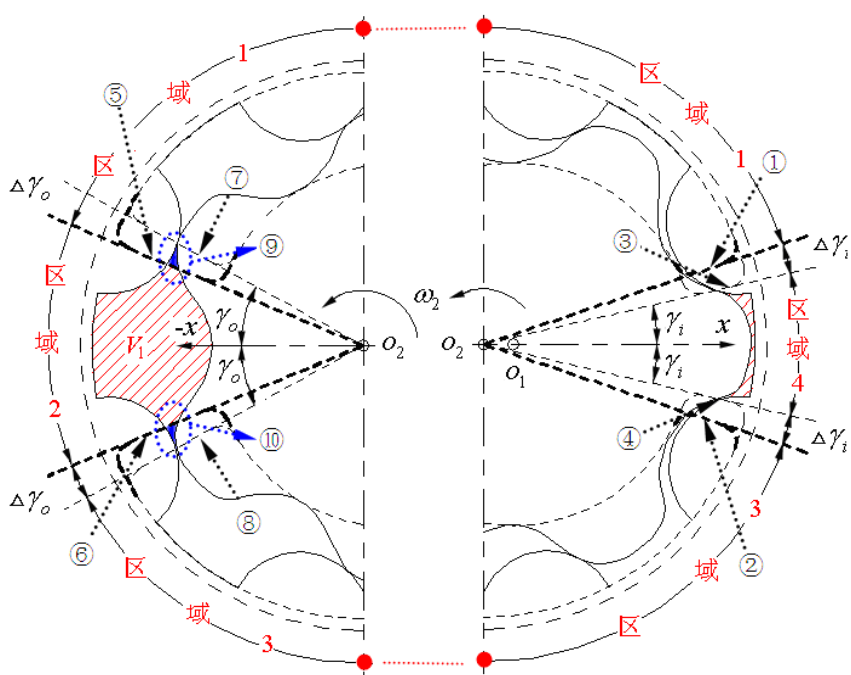

(1) 一吸油腔实际轮廊；(2)—排油腔实际轮廓；(3)—吸油腔理论轮廊；

(4) 一排油腔理论轮廓; (5)一吸油腔实际轮廓; (6)一排油腔实际轮廊;

(7) 一吸油腔理论轮廓; (8) 一排油腔理论轮廓; (9)—吸油侧连通面积;

(10) 一排油侧连通面积

a. 最大位置

\begin{tabular}{|c|c|}
\hline ·吸油腔实际轮廊 & Actual contour of oil absorption cavity \\
\hline 排油腕理论轮序 & Actual contour of oil drainage cavity \\
\hline 吸油腔理论轮序 & Theoretic contour of oil absorption cavity \\
\hline 排油腔理论轮就 & Theoretic contour of oil drainage cavity \\
\hline 吸油䐛实际轮遊 & Actual contour of oil absorption cavity \\
\hline 排油整实际轮麻 & Actual contour of oil drainage cavity \\
\hline 吸油脱理论轮原 & Theoretic contour of oil absorption cavity \\
\hline 排油脱理论轮席 & Theoretic contour of oil drainage cavity \\
\hline 吸油们连通面积 & Connected area of oil absorption side \\
\hline 排油侧连通面积 & Connected area of oil drainage side \\
\hline & Area 1 \\
\hline 2 & Area 2 \\
\hline & Area 3 \\
\hline
\end{tabular}

a. The maximum position b. 最小位置

b. The minimum position

Fig. (3). Theory outline and actual contour in the maximum and minimum volume position.

set as $\gamma_{i}$, and is called the included angle of the oil cavity in the minimum position; and its included angle with - $x$ axis in the maximum position is set as $\gamma_{0}$, and is called the included angle of the oil cavity in the maximum position. But in fact, the density of the sealing area between the oil absorption cavity and oil drainage cavity is often increased at the 
oil absorption site by improving $\Delta \gamma_{\mathrm{i}}$ value appropriately on the basis of $\gamma_{\mathrm{i}}$, so as to improve the volumetric efficiency [1]; and meanwhile, the sufficient oil absorption is often reached at the oil absorption side with the flow inertia of the oil by reducing $\Delta \gamma_{0}$ value appropriately on the basis of $\gamma_{0}$, so as to improve the volumetric efficiency [1]. In order to facilitate the characteristic analysis of the trapped oil, the actual oil absorption cavity and oil drainage cavity are arranged symmetrically, as shown in Fig. (3).

In Fig. (3), when the wheel o2 rotates a circle, V1 goes through the following four areas. Area 1: $\left[\gamma_{\mathrm{i}}+\Delta \gamma_{\mathrm{i}}\right.$, $\left.\pi-\gamma_{0}+\Delta \gamma_{0}\right]$, area 2: $\left[\pi-\gamma_{0}+\Delta \gamma_{0}, \pi+\gamma_{0}-\Delta \gamma_{0}\right]$, area 3: $\left[\pi+\gamma_{0}-\Delta \gamma_{0}\right.$, $\left.2 \pi-\gamma_{\mathrm{i}}-\Delta \gamma_{\mathrm{i}}\right]$, and area 4: $\left[2 \pi-\gamma_{\mathrm{i}}-\Delta \gamma_{\mathrm{i}}, 2 \pi+\gamma_{\mathrm{i}}+\Delta \gamma_{\mathrm{i}}\right]$. $\mathrm{V}_{1}$ in area 1 is always contacted with the oil absorption cavity fully, and $\mathrm{V}_{1}$ in area 2 is a little big relative to the trapped oil flow near the minimum position, but $\mathrm{V}_{1}$ is always contacted with the oil absorption cavity and oil drainage cavity fully, as shown in the connected area of the oil absorption and oil drainage sides in Fig. (3a); and $V_{1}$ in area 3 is always in contact with the oil drainage cavity fully. Therefore, $\mathrm{Q}_{\mathrm{r}} \approx-\mathrm{DV}_{1}$ is present in the three areas, so, the obvious trapping phenomenon is not presented, and it is also not analyzed in detail here. But, $\mathrm{V}_{1}$ in area 4 is small, relative to the trapped oil flow near the maximum position, but $V_{1}$ is not always contacted with the oil absorption cavity and oil drainage cavity, namely, $\mathrm{Q}_{\mathrm{r}}=0$, and the probability of the obvious trapping phenomenon is relatively big, therefore, the focus is on the analysis of trapping characteristics in this area. So, the Formula (9) is simplified into

$\mathrm{d} p_{1} / \mathrm{d} \varphi_{2}=K_{1}\left[-D V_{1}-Q_{n}\left(p_{1}\right)-Q_{o}\left(p_{1}\right)\right] /\left(\omega_{2} V_{1}\right)$

\subsection{Leakage Rate}

For considering machining error and processing cost in the actual production, the meshing clearance of radial tooth top is often taken $\mathrm{h}_{\mathrm{n}}=0.02 * 10^{-3} \mathrm{~m}-0.10^{*} 10^{-3} \mathrm{~m} \mathrm{[1]}$, and the axial clearance of the end face is often taken ho $=0.02 * 10^{-3}$ $\mathrm{m}-0.12 * 10^{-3} \mathrm{~m}[1]$.

In Figs. $(\mathbf{1}, \mathbf{3})$, the wheel $o_{1}$ is taken as the drive wheel, and the power is transmitted by the meshing point located at one side of the oil absorption cavity, so as to push the driven wheel $\mathrm{O}_{2}$ to rotate, therefore, the clearance at these meshing points can be approximated to 0 ; but the power cannot be transmitted at the meshing point located at one side of the oil drainage cavity, therefore, the clearance at these meshing points can be approximated to $h_{n}$ [11-14]. Therefore, the meshing points at one side of the oil drainage cavity are not the meshing points in the true sense, and here, they are defined as the side clearance points; the clearance here is defined as the gear side clearance; and the exchange flow $Q_{n}$ passing through the gear side clearance at the point $\mathrm{n}_{1}$ and $\mathrm{n}_{2}$ is called the side clearance flow. The meshing point $n_{1}$ in Fig. (3) is located at one side of the oil absorption cavity, and the meshing point $\mathrm{n}_{2}$ is located at one side of the oil drainage cavity. So [24],

$$
Q_{n}\left(p_{1}\right)=\operatorname{sign}\left(p_{1}-p_{o}\right) C_{n} b h_{n} \sqrt{2\left|p_{1}-p_{o}\right| / \rho}
$$

In the formula, sign () indicates the positive and negative signs in the bracket, and its value is -1 when being negative and 1 when being positive; $p_{o}$ indicates the oil drainage pressure of the pump; $\rho$ indicates the density of the working oil; and $\mathrm{C}_{\mathrm{n}}$ indicates the flow coefficient of the thinwalled hole.

In Fig. (4a), the axial leakage arisen from the peripheral closed outline of $\mathrm{V}_{1}$ is mainly composed of four parts respectively [28], i.e. quantity $\mathrm{Q}_{01}$ of leakage (1) flowing to $\mathrm{o}_{1}$ and $\mathrm{O}_{2}$ axis, quantity $\mathrm{Q}_{\mathrm{o} 2}$ of leakage (2) flowing to the oil drainage cavity, quantity $\mathrm{Q}_{03}$ of leakage (3) flowing to the oil absorption cavity, and quantity $\mathrm{Q}_{04}$ of leakage (4) flowing to the outer ring of the wheel $\mathrm{O}_{2}$; and the above-mentioned leakage rate is positive for outflow. The path length of the leakage (1) is far more than that of leakage (2) (4), so the leakage (1) can be ignored, namely, $\mathrm{Q}_{0}=\mathrm{Q}_{02}+\mathrm{Q}_{03}+\mathrm{Q}_{04}$.

In Fig. (4a), the included angle of arc section $g_{1} g_{2}$ of the tooth space of the wheel $\mathrm{O}_{2}$ corresponding to the center of the circle of the axis $\mathrm{O}_{2}$ is

$\alpha_{f 2}=2 \pi / z_{2}-2 a \cos \left[\left(L^{2}+r_{f 2}^{2}-R^{2}\right) /\left(2 L r_{f 2}\right)\right]$

In the formula, $\mathrm{r}_{\mathrm{f} 2}$ indicates the root radius of $\mathrm{O}_{2}$; and based on the flow formulate of long and thin hole, $Q_{04}$ is obtained as follows:

$$
Q_{o 4}=\frac{\alpha_{f 2} r_{f 2} h_{o}^{3}}{12 \mu\left(r_{D 2}-r_{f 2}\right)}\left(p_{1}-p_{i}\right)
$$

In the formula, $\mu$ indicates the viscosity of the oil; and $r_{D 2}$ indicates the radius of the outer ring of the wheel $\mathrm{O}_{2}$.

In Fig. (4a), the leakage path of (2) and (3) can be approximated to the trapezoid path shown in Fig. (4b) when the pump is rotated in area 4 . So [28]

$$
\left.\begin{array}{l}
Q_{o 2}\left(\varphi_{2}\right)=\frac{h_{2} h_{o}^{3} \ln \left(b_{2} / a_{2}\right)}{12 \mu\left(b_{2}-a_{2}\right)}\left(p_{1}-p_{o}\right) \\
Q_{o 3}\left(\varphi_{2}\right)=\frac{h_{3} h_{o}^{3} \ln \left(b_{3} / a_{3}\right)}{12 \mu\left(b_{3}-a_{3}\right)}\left(p_{1}-p_{i}\right)
\end{array}\right\}
$$

In the formula, $\mathrm{p}_{\mathrm{i}}$ indicates the oil absorption pressure of the pump.

In Fig. (4a), the point $\mathrm{n}_{2}$ located on the actual contour line of the oil drainage cavity is taken as the initial position of trapping analysis and the included angle of $n_{2}$ to the initial position is set as $\alpha_{2 \mathrm{n}}$, so

$$
\left.\begin{array}{l}
a_{2}=r_{22} \sin \alpha_{2 n} ; \quad b_{2}=r_{f 2} \sin \left(\alpha_{2 n}+\gamma_{i}-0.5 \alpha_{f 2}\right) \\
h_{2}=r_{f 2} \cos \left(\alpha_{2 n}+\gamma_{i}-0.5 \alpha_{f 2}\right)-r_{22} \cos \alpha_{2 n} \\
a_{3}=r_{12} \sin \left(2 \Delta \gamma_{i}-\alpha_{2 n}\right) ; b_{3}=r_{f 2} \sin \left(\gamma_{i}+2 \Delta \gamma_{i}-0.5 \alpha_{f 2}-\alpha_{2 n}\right) \\
h_{3}=r_{f 2} \cos \left(\gamma_{i}+2 \Delta \gamma_{i}-0.5 \alpha_{f 2}-\alpha_{2 n}\right)-r_{22} \cos \left(2 \gamma_{i}+2 \Delta \gamma_{i}-\alpha_{2 n}\right)
\end{array}\right\}
$$

In $\Delta \mathrm{n}_{2} \mathrm{c}_{2} \mathrm{O}_{2}$, set $\angle \mathrm{n}_{2} \mathrm{c}_{2} \mathrm{O}_{2}=\theta_{2}$, rad; and in $\Delta \mathrm{n}_{1} \mathrm{c}_{1} \mathrm{O}_{2}$, set $\angle \mathrm{n}_{1} \mathrm{c}_{1} \mathrm{o}_{2}=\theta_{1}$, rad, so

$$
\left.\begin{array}{l}
r_{12}\left(\varphi_{2}\right)=\sqrt{L^{2}+R^{2}-2 L R \cos \theta_{1}} \\
r_{22}\left(\varphi_{2}\right)=\sqrt{L^{2}+R^{2}-2 L R \cos \theta_{2}}
\end{array}\right\}
$$

Wherein, in $\Delta \mathrm{c}_{1} \mathrm{O}_{2} \mathrm{p}$ and $\Delta \mathrm{c}_{2} \mathrm{O}_{2} \mathrm{p}$, the following formula can be obtained according to the geometrical relationship of triangle: 
$\left.\begin{array}{l}r_{2} \sin \left(\pi-\theta_{1}-\varphi_{2}\right)=L \sin \theta_{1} \\ r_{2} \sin \left[\pi-\theta_{2}-\left(\varphi_{2}-2 \pi / z_{2}\right)\right]=L \sin \theta_{2}\end{array}\right\}$

In $\Delta \mathrm{n}_{2} \mathrm{O}_{2} \mathrm{p}$, set $\angle \mathrm{n}_{2} \mathrm{O}_{2} \mathrm{p}=\alpha_{2}$, so

$\alpha_{2 n}\left(\varphi_{2}\right)=\gamma_{i}+\Delta \gamma_{i}-\alpha_{2}\left(\varphi_{2}\right)$

And, in $\Delta \mathrm{n}_{2} \mathrm{O}_{2} \mathrm{p}$,

$\alpha_{2}\left(\varphi_{2}\right)=a \cos \left[r_{22}^{2}\left(\varphi_{2}\right)+r_{2}^{2}-f_{2}^{2}\left(\varphi_{2}\right)\right] /\left[2 r_{22}\left(\varphi_{2}\right) r_{2}\right]$

In Fig. (3b), if the corner deviation of theoretical and actual contour at two sides of the oil absorption cavity and oil drainage cavity relative to the wheel $\mathrm{o}_{2}$ is set as $\Delta \varphi_{2}$, namely, the value range of $\varphi_{2}$ is $\left[\pi / z_{2}-\Delta \varphi_{2}, \pi / z_{2}+\Delta \varphi_{2}\right]$. So, $\varphi_{2}=\pi / z_{2}$ is substituted into the Formula (19), and at this time, $\alpha_{2}$ is equal to $\gamma_{i}$; and $\varphi_{2}=\pi / z_{2}-\Delta \varphi_{2}$ is substituted into the formula (19), and at this time, $\alpha_{2}$ is equal to $\gamma_{\mathrm{i}}+\Delta \gamma_{\mathrm{i}}$, namely

$\gamma_{i}=\alpha_{2}\left(\pi / z_{2}\right) \quad ; \Delta \gamma_{i}=\alpha_{2}\left(\pi / z_{2}-\Delta \varphi_{2}\right)-\gamma_{i}$

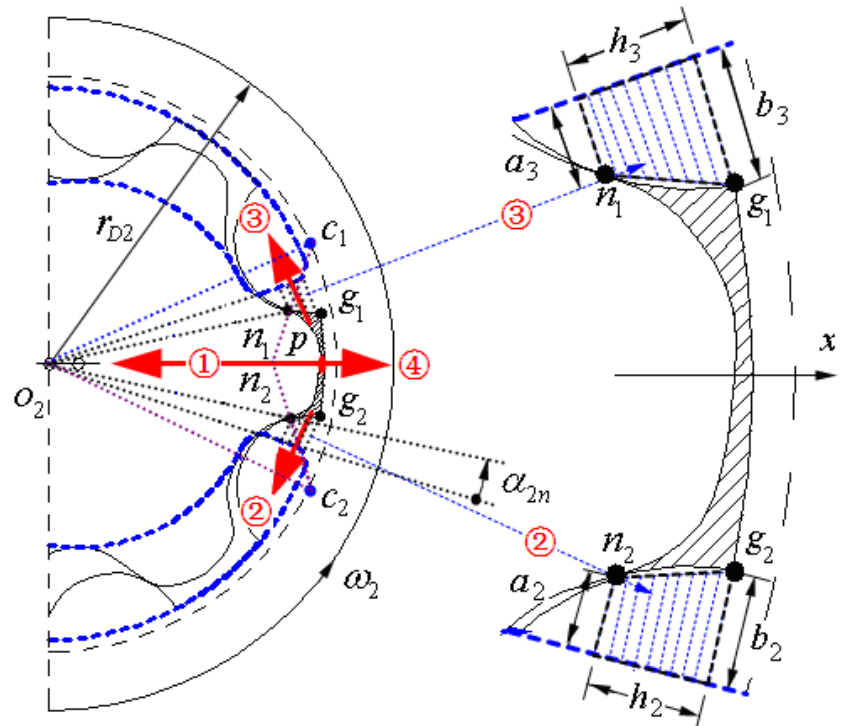

\section{a. 轴问泄漏}

b. 放大图(3.2:1)

a. Axial leakage

b. Local amplification $(3.2: 1)$

Fig. (4). Axial leakage paths near the minimum volume position.

\section{INSTANCE ANALYSIS OF TRAPPING CHARACTERISTICS}

Based on the relevant parameters in Part 2, the calculation by taking $\mathrm{r}_{\mathrm{D} 2}=1.5 \mathrm{r}_{\mathrm{f} 2}, \mathrm{r}_{\mathrm{f} 2}$ again is shown in the literature [1, 19]; and the speed of the wheel $o_{1}$ is taken for $5000 \mathrm{r} / \mathrm{min}, \mathrm{p}_{\mathrm{i}}=1 * 10^{5} \mathrm{~Pa} ; \mathrm{p}_{\mathrm{o}}=10^{*} 10^{5} \mathrm{~Pa}, \mathrm{~h}_{\mathrm{o}}=0.03 \times 10^{-3} \mathrm{~m}$; $\mathrm{h}_{\mathrm{n}}=0.03 \times 10^{-3} \mathrm{~m}, \mu=0.09$ Pa.s, $\mathrm{C}_{\mathrm{n}}=0.62, \mathrm{~K}_{1}=1.7 \times 10^{9} \mathrm{~Pa}$, $\rho=870 \mathrm{Kg} / \mathrm{m}^{3}$. The trapping model shown in the formula (10) is subjected to the simulation calculation with Runge-Kutta method [24], and the iterations $\mathrm{N}$ are taken for 50000. So the trapped oil pressure corresponding to $\Delta \varphi_{2}=0.5^{\circ}, 1^{\circ}$ and $2^{\circ}$ and various flows corresponding to $\Delta \varphi_{2}=1^{\circ}$ are shown in Fig. (5).

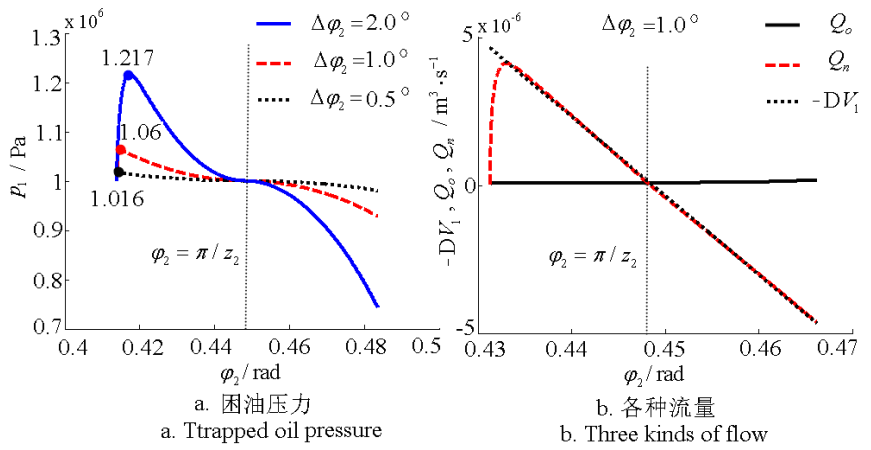

Fig. (5). Trapped oil pressure and all flows in the position of minimum volume.

In Fig. (5a), when $\Delta \varphi_{2}$ is changed from $0.5^{\circ}$ to $1^{\circ}$, until to $2^{\circ}$, the maximum peak of the trapped oil pressure is changed from $1.016^{*} 10^{6} \mathrm{~Pa}$ to $1.06^{*} 10^{6} \mathrm{~Pa}$, until to $1.217 * 10^{6} \mathrm{~Pa}$, the trapping phenomenon is gradually obvious, and the pressure peak is $1.6 \%, 6.0 \%$ and $21.7 \%$ respectively, relative to the increasing percentage of the outlet pressure.

In Fig. (5b), the trapped oil flow $-\mathrm{DV}_{1}$ is mainly relieved by the side clearance flow $\mathrm{Q}_{\mathrm{n}}$, namely, $\mathrm{Q}_{\mathrm{n}} \approx-\mathrm{DV}_{1}$, therefore, the gear side clearance shall be reduced as far as possible. The axial flow is $\mathrm{Q}_{\mathrm{o}}<<\mathrm{Q}_{\mathrm{n}}$, namely, $\mathrm{Q}_{\mathrm{o}} \approx 0$. Thus, it can also obtain the simplest trapping model

$$
\frac{\mathrm{d} p_{1}}{\mathrm{~d} \varphi_{2}}=\frac{K_{1}}{\omega_{2} V_{1}}\left[-\mathrm{D} V_{1}\left(\varphi_{2}\right)-Q_{n}\left(p_{1}, \varphi_{2}\right)\right]
$$

\section{CONCLUSION}

1) Under the parameters of the case, the non-uniform coefficient of $6.45 \%$ flow of the cycloid rotor pump is much better than that of $21.2 \%$ flow of the external gear pump with the tooth number 10 , and the pulse frequency of the flow is consistent with that of the external gear pump which is provided with the side clearance. It can be seen that the flow characteristics of the cycloid rotor pump are far better than that of the external gear pump.

2) Under the parameters of the case, the calculation errors of the two approximation formulas for the flow calculation are $1.93 \%$ and $2.90 \%$ respectively; the approximation error of the non-uniform coefficient of the flow is $7.13 \%$, and the approximation error of the flow is relatively small and conforms to the actual requirement of the engineering, but the approximation error of the non-uniform coefficient of the flow is on the high side and relative to the external gear pump. The trapping phenomenon is also presented by the cycloid rotor pump, but is not obvious.

3) In practice, it is theoretically practicable to improve the volumetric efficiency by increasing the included position of the oil cavity in the minimum position and decreasing the included angle of the oil cavity in the maximum position. 
4) The relative big side clearance leakage is presented by the rotor pump, therefore, the meshing clearance value of the radial tooth top shall be reduced as far as possible; and the axial leakage is far less than the side clearance leakage, therefore, the axial clearance value can be increased appropriately due to the process demand.

\section{CONFLICT OF INTEREST}

The authors confirm that this article content has no conflict of interest.

\section{ACKNOWLEDGEMENTS}

Declared none.

\section{REFERENCES}

[1] X. Xu, The Internal Meshing Cycloid Gear Pump Theory Research and Simulation, Nanjing: Southeast University, 2005.

[2] D. Vecchiato, A. Demenego, J. Argyris, and F. L. Litvin, "Geometry of a cycloidal pump," Computer Methods in Applied Mechanics and Engineering, vol. 190, no. 18, pp. 2309-2330, 2001.

[3] F.L. Litvin, and P. Feng, "Computerized design and generation of cycloidal gearings," Mechanism and Machine Theory, vol. 31, no. 7,pp. 891-911, 1996

[4] A. Demeneg, D. Vecchiato, and F.L. Litvin, "Design and simulation of meshing of a cycloidal pump," Mechanism and Machine Theory, vol. 37, no. 3, pp. 311-332, 2002.

[5] G.C. Mimmi, and P.E. Pennacchi, "Non-undercutting conditions in internal gears," Mechanism and Machine Theory, vol. 35, no. 4, pp. 477-490, 2000.

[6] S.C. Lee, "Profile design of the inner rotor of a gerotor by the composite curve of circular arcs," Journal of the KSTLE, vol. 22, no. 2, pp. 79-86, 2006.

[7] C.F. Hsieh, and J.H. Hwang, "Geometric design for a gerotor pump with high area efficiency," ASME Journal of Mechanics, vol. 129, no. 12, pp. 1269-1277, 2007.

[8] C.F. Hsieh, "Influence of gerotor performance in varied geometrical design parameters," ASME Journal of Mechanics, vol. 131 , no. 12, 2009.

[9] T.H. Choi, M.S. Kim, G.S. Lee, S.Y. Jung, J.H. Bae and C. Kim, "Design of rotor for internal gear pump using cycloid and circulararc curves," Journal of Mechanical Design, vol. 134, no.1, pp. 011005-1-011005-12, 2012

[10] Y. Inaguma, "Friction torque characteristics of an internal gear pump," Proceedings of the Institution of Mechanical Engineers, Part C: Journal of Mechanical Engineering Science, vol. 225, no. 6, pp.1523-1534, 2011.

[11] Y.J. Chang, J.H. Kim, C.H. Jeon, C. Kim and S.Y. Jung, "Development of an integrated system for the automated design of a gerotor oil pump," ASME Journal of Mechanics, vol. 129, no.10, pp. 1099-1105, 2012.
[12] B. Paffoni, R. Progri and R. Gras, "Teeth clearance effects upon pressure and film thickness in a trochoidal hydrostatic gear pump," In: Proceedings of the Institution of Mechanical Engineers, Part G: Journal of Aerospace Engineering, vol. 218, no.4, pp. 247-256, 2004.

[13] L. Ivanovic, G. Devedzic, S. Cukovic, and N. Mirić, "Modeling of the meshing of trochoidal profiles with clearances, Journal of Mechanical Design, vol. 134, no. 4, pp. 041003-1-041003-9, 2012.

[14] G.S. Lee, S.Y. Jung, J.H. Bae, L.T. Ivanović, M.D. Erić, B.Ž Stojanović, and A.B. Ilić, "Determination of tooth clearances at trochoidal pump," FME Transactions, vol. 39, no. 3, pp. 117-126, 2011.

[15] S.M. Kwon, C.H. Kim, and J.H. Shin, "Optimal rotor wear design in hypotrochoidal gear pump using genetic algorithm," Journal of Central South University, vol. 18, no. 3, pp. 718-725, 2011.

[16] Z. Wang, and Z. Liu, "Parameter design and anlaysis of internal meshing cyclodial gear pump," Journal of mechanical transmission, vol. 34, no. 2, pp. 35-40, 2010.

[17] Y. Xu, W. Chen, and S. Han, "Parameter equation of cycloid pump inner rotor theoretic profile curve and modeling of inner-outer rotor," Machine Tool \& Hydraulics, vol. 36, no.1, pp.106-107, 2008.

[18] W. Luo, W. Qiu, R. Shu, L.V. Wei, "Study analysis on interior tooth of arc-cycloidal gear pump tooth shape," Coal Mine Machinetry, vol. 29, no. 4, pp. 63-65, 2008.

[19] G. Li, "Design calculation of cycloid rotary pump," Modern Vehicle Power, vol. 125, no. 1, pp. 40-42, 2007.

[20] X. Xu, "Optimization of the design parameters of cycloidal pump with singularity type profile," Fluid Machinetry, vol. 33, no. 2, pp. 20-23, 2005

[21] S. Feng, X. Gao, and W. Liu, "Calculation and analysis on volume of working chambers for internal-meshing compressor," China Mechanical Engineering, vol. 19, no. 16, pp. 1903-1907, 2008.

[22] C. He, "Hydraulic components," China Machine Press: Beijing, 1985 (in Chinese)

[23] G. Yang, G. Bai, and S. Zhang, "Analysis of trapping oil characteristics of straight conjugate internal gear pump," New Technology \& New Process, vol. 2, pp. 51-54, 2012.

[24] Y. Li, Mechanism, modeling and experiment Investigation of trapped oil in external gear pump, Hefei University of Technology: Hefe, 2009, (in Chinese with English abstract).

[25] M. Eaton, P. S. Keogh, and K. A. Edge, "The modeling, prediction and experimental evaluation of gear pump meshing pressures with particular reference to aero-engine fuel pumps," In: Proceedings of the Intitution of Mechanical Engineers Part I-Journal of Systems and Control Engineering, vol. 220, no. 5, pp. 365-379, 2008.

[26] Y. Li, and K. Liu, "Dynamic model of trapped oil and effect of related variables on trapped oil pressure in external spur-gear pump," Transactions of the Chinese Society of Agricultural Engineering, vol. 40, no. 9, pp. 214-219, 2009.

[27] Y. Li, "Summary of research and development of trapped-oil phenomenon and trapped-oil model," Journal of Chengdu University (Natural Science), vol. 30, no. 2, pp. 172-177, 2011.

[28] Y. Li, "Establishment and verification of analytic formula for imum trapped-oil pressure in external gear pump," Transactions of the Chinese Society of Agricultural Engineering, vol. 29, no. 11, pp. 71-77, 2013. 